\title{
Eficácia e seletividade do metribuzin e diuron em pré-transplantio do tomate sob diferentes coberturas vegetais
}

\author{
Efficacy and selectivity of metribuzin and diuron in pre-transplanting of \\ tomato crop under with different cover crops species
}

Jéssica Karina Guedes Cavalcante ${ }^{1}$, Kassio Ferreira Mendes ${ }^{2 *}$, Miriam Hiroko Inoue ${ }^{1}$, Paulo Ricardo Junges dos Santos ${ }^{1}$, Ana Paula da Silva Fonseca ${ }^{1}$, Edyane Luzia Pires Franco ${ }^{1}$

Resumo - O tomate é uma olerícola que apresenta baixa tolerância à maioria dos herbicidas recomendados, fato que limita a utilização de produtos químicos no manejo integrado de plantas daninhas. Assim, o objetivo deste trabalho foi avaliar a eficácia e a seletividade do metribuzin e diuron, aplicados na modalidade pré-transplantio do tomate cultivado sobre diferentes coberturas vegetais. As sementes de tomate cv. IPA 6 foram semeadas em bandejas e transplantadas para os vasos no estádio de duas folhas verdadeiras. As coberturas usadas foram: solo exposto (controle), Urochloa ruziziensis $\left(0,30 \mathrm{t} \mathrm{ha}^{-1}\right)$, Pennisetum glaucum $\left(0,42 \mathrm{t} \mathrm{ha}^{-1}\right)$ e comunidade infestante $\left(0,39 \mathrm{t} \mathrm{ha}^{-1}\right)$, acondicionadas nos vasos antes da aplicação dos herbicidas. A fitotoxicidade dos herbicidas, a altura de plantas e a eficácia dos mesmos foram avaliadas aos 7, 14, 21, 28 e 35 dias após a aplicação (DAA), sendo que no último dia de avaliação também foi mensurada a massa seca de folhas, caule e raízes. Quanto à seletividade, o metribuzin proporcionou injúrias leves de fitointoxicação nas mudas, porém sem refletir em perdas na biomassa seca. Apesar da eficácia, o diuron não foi seletivo ao tomate, causando altos percentuais de fitointoxicação (65 a 100\%). Conclui-se que a cobertura do solo com $U$. ruziziensis, $P$. glaucum e comunidade infestante complementou a ação de ambos os herbicidas, mas apenas o metribuzin foi seletivo quando aplicado em pré-transplantio do tomate.

Palavras-chave: fitointoxicação, manejo integrado de plantas daninhas, Solanum lycopersicum

Abstract - The tomato plant is an oleraceous that has low tolerance to most of the herbicides used, which limits the use of chemical products in integrated weed management. By this fact, this study was conducted for evaluating the efficacy and selectivity of the metribuzin and diuron, both applied before transplanting the tomato crop, upon different cover crops. Seeds of tomato cv. IPA 6 were planted in trays and transplanted to pots at the stage of two leaves. The species used were: exposed soil (control), Urochloa ruziziensis $\left(0.30 \mathrm{t} \mathrm{ha}^{-1}\right)$, Pennisetum glaucum $\left(0.42 \mathrm{tha}^{-1}\right)$ and weed community $\left(0.39 \mathrm{t} \mathrm{ha}^{-1}\right)$, being of herbicide application. The phytotoxicity, efficacy and plant height were evaluated at 7, 14, 21, 28 and 35 days after application (DAA), and in the last evaluation day it was also measured the dry mass of leaves, stem and roots. Regarding the selectivity, the metribuzin provided low phytointoxication in the seedlings, with no effects in the biomass. Despite the efficacy, diuron was not selective to tomato, causing high phytotoxification rates (65 to 100\%). It was concluded that the treatment covered with $U$. ruziziensis, $P$. glaucum and weed community supplemented the both herbicides action, but only metribuzin was selective when applied in tomato pre-transplanting. Keywords: phytointoxication, weed integrated management, Solanum lycopersicum

Recebido: Agosto 07, 2018. Aceito: Janeiro 17, 2019.

${ }^{1}$ Departamento de Agronomia, Universidade do Estado de Mato Grosso - UNEMAT, Tangará da Serra, MT, Brasil. E-mail: jessicakarinajk@hotmail.com;miriamhinoue@hotmail.com; pauloricardojunges@hotmail.com; apfonseca@hotmail.com; edyaneflor@hotmail.com

2 Departamento de Fitotecnia, Universidade Federal de Viçosa - UFV, Avenida Peter Henry Rolfs, s/n, Campus Universitário, CEP 36570-900, Viçosa, MG, Brasil. E-mail: kassio_mendes_06@hotmail.com 


\section{Introdução}

O tomate (Solanum lycopersicum L.), pertencente à família Solanaceae, é uma das hortaliças de maior importância econômica no mundo, tendo seu desenvolvimento limitado pela ocorrência de deficiências nutricionais, doenças, nematóides, pragas e plantas daninhas. Neste sentido, as plantas daninhas podem causar perdas de até $75 \%$ na cultura, já que interferem no porte das plantas, reduzindo o tamanho dos frutos e, consequentemente a produtividade (Nascente et al., 2004; Filgueira, 2008). Para restringirem essas perdas, o tomate cultivado sob o sistema de plantio direto (SPD), consagra-se como uma técnica a ser implementada pelo horticultor, a fim de desenvolver uma agricultura mais sustentável e que acarrete na supressão das inúmeras plantas daninhas presentes na cadeia produtiva, bem como proporcione condições ideais de solo para o cultivo da olerícola (Hirata et al., 2009; Wamser et al., 2010; Valmorbida et al., 2012).

Em tal sistema, a cobertura do solo torna-se um método complementar ao controle químico das plantas daninhas. Nesse viés, tem aumentado no tomate industrial, o emprego de poáceas e eudicotiledôneas forrageiras visando fornecer cobertura para o solo e, minimizar a matocompetição. Ademais, evidencia a preocupação dos agricultores em diminuir o número de pulverizações, ampliando a rentabilidade da produção e reduzindo os impactos ambientais oriundos da atividade agrícola (Hirata et al., 2009).

O controle das plantas daninhas na área de cultivo de tomate é obtido, principalmente, por meio da aplicação de herbicidas. No entanto, esta cultura apresenta baixa tolerância à maioria dos produtos empregados, além de existirem poucos herbicidas registrados e com pequeno espectro de controle (Ormeño et al., 2003; Ronchi et al., 2010).

Dentre os herbicidas registrados para a cultura do tomate, destaca-se o metribuzin, que atua na inibição do transporte de elétrons do fotossistema
II e controla exclusivamente plantas daninhas eudicotiledôneas. Todavia, pode intervir no desenvolvimento dessa cultura, em virtude da possibilidade de promover fitotoxicidade, quando dias nublados antecedem a aplicação, ou, quando há alta disponibilidade de água no solo (Bachega et al., 2005). Outro herbicida que também interfere no fotossistema II é o diuron, pertencente ao grupo das uréias e registrado para controlar monocotiledôneas e eudicotiledôneas em abacaxi, cana-de-açúcar, citros, café, algodão, videira, cacau, banana, alfafa e seringueira (Oliveira Júnior, 2011; Brasil, 2018).

Diante da quantidade limitada de produtos existentes no Brasil, muitos produtores empregam herbicidas que não são registrados à determinada cultura, sobretudo para controlar espécies já tolerantes ao metribuzin, tais como o leiteiro (Euphorbia heterophylla) e a maria-pretinha (Solanum americanum) (Ronchi et al., 2010; Silva et al., 2010; Vargas et al., 2016).

Perante tal problemática, são imprescindíveis estudos que avaliem a seletividade de herbicidas no cultivo de tomate e a potencialização da ação dos mesmos, decorrente da associação com coberturas vegetais. Com base no exposto, o objetivo deste trabalho foi avaliar a eficácia e a seletividade do metribuzin e diuron aplicados na modalidade de pré-transplantio do tomate cultivado sobre diferentes coberturas vegetais.

\section{Material e métodos}

$\mathrm{O}$ experimento foi conduzido durante o período de fevereiro a agosto de 2017, em condições de campo e de casa de vegetação, na área experimental da Universidade do Estado de Mato Grosso, Campus Universitário Professor Eugênio Carlos Stieler, localizada em Tangará da Serra, Mato Grosso. A altitude do local é de aproximadamente 321,5 metros, com latitude $14^{\circ} 39^{\prime} \mathrm{S}$ e longitude $57^{\circ} 27^{\prime} \mathrm{O}$.

O delineamento experimental adotado foi o inteiramente casualizado com 4 repetições, em esquema fatorial $3 \times 4$, sendo o primeiro 
fator constituído pelas aplicações de herbicidas (metribuzin, diuron e testemunha sem aplicação) e o segundo pelas coberturas (solo exposto, Urochloa ruziziensis, comunidade infestante e Pennisetum glaucum), totalizando 12 tratamentos dispostos em vasos de $3 \mathrm{~L}$, compostos por duas plantas de tomate em cada.

Para obter as coberturas em campo, foram semeadas a lanço, no mês de fevereiro, Pennisetum glaucum cv. BRS 1501 e Urochloa ruziziensis cv. ruziziensis em parcelas com dimensão de 4x5 m. Além das parcelas semeadas com as coberturas, foram mantidas parcelas em pousio para o crescimento livre da comunidade infestante. Para a determinação das espécies que compunham a comunidade infestante efetuou-se um levantamento pelo método do quadrado inventário de $0,25 \mathrm{~m}^{2}$, lançado aleatoriamente nas parcelas mantidas em pousio. As plantas daninhas foram contabilizadas e identificadas em família, gênero e espécie, e são descritas na Tabela 1. A comunidade infestante da área experimental era composta, predominantemente, por: capim-camalote $(24,12 \%)$, poia-branca (17,98\%), erva-de-passarinho $(14,04 \%)$ e apaga-fogo $(10,96 \%)$.

Para a coleta do resíduo vegetal das coberturas, foi realizada a dessecação prévia uma semana antes do transplantio das mudas de tomate para os vasos, empregando o glyphosate na dose de 1440 g e.a. ha ${ }^{-1}$, aos 120 dias após o plantio (DAP) das coberturas, sendo que após uma semana utilizou-se um rolo-faca para acamar as plantas das parcelas. As palhadas provenientes das coberturas foram acondicionadas nos vasos antes da aplicação dos herbicidas, nas seguintes quantidades: Brachiaria ruziziensis $\left(0,30 \mathrm{t} \mathrm{ha}^{-1}\right)$, Pennisetum glaucum $\left(0,42 \mathrm{t} \mathrm{ha}^{-1}\right)$ e comunidade infestante $\left(0,39 \mathrm{t} \mathrm{ha}^{-1}\right)$.

Os vasos foram preenchidos com solo obtido de área isenta de aplicação de produtos químicos durante 6 meses, situada na área experimental já citada. O solo foi coletado na camada de $0-20 \mathrm{~cm}$, peneirado e os atributos físico-químicos do mesmo se encontram na Tabela 2. Segundo a EMBRAPA (2013), o solo foi classificado como um Latossolo Vermelho Distroférrico de textura argilosa.

Tabela 1. Caracterização da comunidade infestante emergida nas parcelas em pousio. Tangará da Serra, MT. 2017.

\begin{tabular}{|c|c|c|c|c|c|}
\hline Nome popular & Nome científico & Família & $\mathbf{V}^{1}$ & $\mathbf{R}^{2}$ & Total $\left(\mathrm{m}^{-2}\right)$ \\
\hline Angiguinho & Aeschynomene denticulata & Fabaceae & 4 & 0 & 4 \\
\hline Apaga-fogo & Alternanthera tenella & Amaranthaceae & 56 & 44 & 100 \\
\hline Botão-de-ouro & Galinsoga quadriradiata & Asteraceae & 12 & 0 & 12 \\
\hline Capim-camalote & Rottboellia cochinchinensis & Poaceae & 180 & 40 & 220 \\
\hline Capim-pé-de-galinha & Eleusine indica & Poaceae & 8 & 20 & 28 \\
\hline Corda-de-viola & Ipomoea purpurea & Convolvulaceae & 24 & 48 & 72 \\
\hline Erva-de-passarinho & Stellaria media & Caryophyllaceae & 80 & 48 & 128 \\
\hline Erva-de-santa-luzia & Chamaesyce hirta & Euphorbiaceae & 16 & 8 & 24 \\
\hline Erva-quente & Spermacoce latifolia & Rubiaceae & 16 & 0 & 16 \\
\hline Falsa-serralha & Emilia fosbergii & Asteraceae & 8 & 16 & 24 \\
\hline Fedegoso & Senna occidentalis & Fabaceae & 16 & 32 & 48 \\
\hline Guanxuma & Sida rhombifolia & Malvaceae & 12 & 8 & 20 \\
\hline Malva-branca & Sida cordifolia & Malvaceae & 8 & 16 & 24 \\
\hline Malva-estrela & Wissadula subpeltata & Malvaceae & 4 & 20 & 24 \\
\hline Poaia-branca & Richardia brasiliensis & Rubiaceae & 128 & 36 & 164 \\
\hline Trapoeraba & Commelina benghalensis & Commelinaceae & 4 & 0 & 4 \\
\hline Total & & & & & 912 \\
\hline
\end{tabular}

${ }^{1}$ Plantas por $\mathrm{m}^{2}$ em estádio vegetativo; ${ }^{2}$ Plantas por $\mathrm{m}^{2}$ em estádio reprodutivo. 
Tabela 2. Atributos físico-químicos do solo presente na unidade experimental. Tangará da Serra, MT. 2017.

\begin{tabular}{|c|c|c|c|c|c|c|}
\hline \multirow{2}{*}{$\begin{array}{c}\mathrm{pH} \\
\left(\mathrm{H}_{2} \mathrm{O}\right)\end{array}$} & $\mathbf{A l}^{3+}$ & & & & $\mathrm{Ca}^{2+}$ & $\mathbf{M g}^{2+}$ \\
\hline & \multicolumn{6}{|c|}{$\left(\mathrm{cmol}_{\mathrm{c}} \mathrm{dm}^{-3}\right)$} \\
\hline 5,70 & 0,00 & & & & 2,36 & 1,10 \\
\hline $\mathbf{K}^{+}$ & $\mathbf{P}$ & MO & $\mathbf{V}$ & Areia & Silte & Argila \\
\hline$\left(\mathrm{cmol}_{\mathrm{c}} \mathrm{dm}^{-3}\right)$ & $\left(\mathrm{mg} \mathrm{dm}^{-3}\right)$ & $\left(\mathrm{g} \mathrm{dm}^{-3}\right)$ & $(\%)$ & & $\left(\mathrm{g} \mathrm{kg}^{-1}\right)$ & \\
\hline 0,28 & 4,30 & 33,00 & 43,79 & 292,00 & 134,00 & 574,00 \\
\hline
\end{tabular}

Fonte: Laboratório Plante Certo, Várzea Grande, MT.

As sementes de tomate cv. IPA 6 foram semeadas em bandejas contendo o substrato comercial Bioplant ${ }^{\circledR}$ e transplantadas para os vasos no estádio de duas folhas verdadeiras. A aplicação do metribuzin e diuron foi realizada nos vasos $2 \mathrm{~h}$ antes do transplantio das mudas de tomate, utilizando-se um pulverizador costal pressurizado a $\mathrm{CO}_{2}$, equipado com seis pontas do tipo XR 110.02, com volume de calda equivalente a $150 \mathrm{~L} \mathrm{ha}^{-1}$ e pressão de $300 \mathrm{kPa}$, nas doses de 480 e 96 g i.a. ha ${ }^{-1}$, respectivamente. Decorridas 24 horas da aplicação dos herbicidas, os vasos foram irrigados manualmente com lâmina diária de $20 \mathrm{~mm}$.

A fitotoxicidade causada por ambos os herbicidas foi aferida visualmente aos 7, 14, 21, 28 e 35 dias após a aplicação (DAA), adotando-se uma escala de notas variando de 0 (zero) a $100 \%$ (cem), onde 0 representa a ausência de sintoma nas plantas e 100 a morte total das mesmas (SBCPD, 1995).

O controle dos herbicidas foi avaliado no mesmo período, por meio de uma escala visual e percentual de notas adaptada por Perim et al. (2009), que varia de 0 (zero) a 100 (cem), na qual zero corresponde à ausência de controle e cem ao controle total e, que baseia-se na preconizada pela Asociación Latino Americana de Malezas (ALAM, 1974). As plantas daninhas emergidas nas unidades experimentais foram identificadas em espécie, aos 35 DAA (Tabela 3).

A altura das plantas foi determinada aos $7,14,21,28$ e 35 DAA, através de uma régua graduada em centímetros, medindo-se a partir do colo da planta até a inserção da última folha. Aos 35 DAA, as plantas de tomate foram coletadas, fracionadas em folhas, caule e raízes, lavadas com água corrente e, posteriormente, acondicionadas em sacos de papel e levadas à estufa de circulação de ar para secagem durante $48 \mathrm{~h}$, sob temperatura constante de $60^{\circ} \mathrm{C}$. Após a secagem, foram realizadas as pesagens em balança de precisão para determinar a massa seca de folhas, caule e raízes.

Os dados obtidos foram submetidos à análise de variância (ANOVA), e quando houve significância pelo teste $\mathrm{F}$, as médias foram comparadas pelo teste de Scott-Knott $(p<0,05)$. Os dados de fitointoxicação $(7,14,21,28$ e 35 DAA) e massa seca (folhas, caule e raízes) foram transformados por $\sqrt{Y+0,5-\operatorname{SQRT}(Y+0,5)}$, sendo que SQRT designa uma função voltada ao cálculo de raiz quadrada, indicada para reduzir a heterogeneidade das variâncias.

\section{Resultados e discussão}

A análise de variância não revelou efeito significativo $(p>0,05)$ da interação herbicida $\mathrm{x}$ cobertura para as variáveis: fitotoxicidade $(14,21,28$ e 35 DAA), controle (28 e 35 DAA) e altura $(7,14,21,28$ e 35 DAA), constatando-se, somente, o efeito simples do fator herbicida $(p<0,01)$.

Aos 7 DAA, constatou-se que as mudas de tomate transplantadas após a aplicação do metribuzin apresentaram sintomas iniciais de fitointoxicação (Tabela 4), caracterizados por uma leve clorose nas folhas. Ademais, verificou-se que 
Tabela 3. Relação das espécies de plantas daninhas emergidas aos 35 dias de avaliação nas unidades experimentais. Tangará da Serra, MT. 2017.

\begin{tabular}{|c|c|c|c|}
\hline \multicolumn{4}{|c|}{ Diuron } \\
\hline \multicolumn{4}{|c|}{ Coberturas } \\
\hline Solo exposto & U. ruziziensis & C. infestante & P. glaucum \\
\hline Alternanthera tenella & Cyperus rotundus & Phyllanthus tenellus & Alternanthera tenella \\
\hline Eclipta alba & Eclipta alba & Brachiaria decumbens & Eclipta alba \\
\hline Diodella teres & Diodella teres & & Diodella teres \\
\hline Phyllanthus tenellus & & & \\
\hline Brachiaria decumbens & & & \\
\hline \multicolumn{4}{|c|}{ Metribuzin } \\
\hline \multicolumn{4}{|c|}{ Coberturas } \\
\hline Solo exposto & U. ruziziensis & C. infestante & P. glaucum \\
\hline Eclipta alba & Diodella teres & Diodella teres & Eclipta alba \\
\hline Diodella teres & Commelina benghalensis & Brachiaria decumbens & Diodella teres \\
\hline Phyllanthus tenellus & Cyperus rotundus & Commelina benghalensis & Phyllanthus tenellus \\
\hline Brachiaria decumbens & & Cyperus rotundus & Digitaria sp. \\
\hline Digitaria $s p$ & & & \\
\hline Cyperus rotundus & & & \\
\hline \multicolumn{4}{|c|}{ Testemunha } \\
\hline \multicolumn{4}{|c|}{ Coberturas } \\
\hline Solo exposto & U. ruziziensis & C. infestante & P. glaucum \\
\hline Alternanthera tenella & Eclipta alba & Alternanthera tenella & Bidens pilosa \\
\hline Eclipta alba & Bidens pilosa & Bidens pilosa & Digitaria sp. \\
\hline Diodella teres & Phyllanthus tenellus & Brachiaria decumbens & Emilia sonchifolia \\
\hline Bidens pilosa & Digitaria sp. & Digitaria sp. & Cyperus rotundus \\
\hline Phyllanthus tenellus & Commelina benghalensis & & \\
\hline Brachiaria decumbens & & & \\
\hline Digitaria $s p$ & & & \\
\hline Commelina benghalensis & & & \\
\hline Eleusine indica & & & \\
\hline Richardia brasiliensis & & & \\
\hline Cyperus rotundus & & & \\
\hline
\end{tabular}

não houve diferença entre as coberturas quando analisado a testemunha sem aplicação tal como para o diuron, responsável pelas maiores notas de fitointoxicação. Entretanto, houve diferença entre as coberturas quando aplicado o metribuzin, sobressaindo-se os tratamentos de solo exposto e $P$. glaucum com as maiores notas.

Observou-se que aos 14 DAA, o diuron proporcionou níveis de fitotoxicidade de $100 \%$, caracterizando injúrias irreversíveis, isto é, a morte das plantas. Também constatou-se que o metribuzin ocasionou intoxicação média de 30\%, tolerada pelas plantas de tomate.
Aos 21 DAA, as plantas de tomate apresentaram as mesmas notas de fitointoxicação observadas aos 14 DAA, tanto para metribuzin quanto para diuron (Tabela 4). Notou-se que aos 28 DAA houve uma estabilização das notas de fitotoxicidade provocada pelo metribuzin, demonstrando que as plantas de tomate iniciaram o processo de recuperação.

Na última avaliação de fitointoxicação, realizada aos 35 DAA, averiguou-se que o metribuzin promoveu os menores níveis de intoxicação em relação ao diuron. Esse último promoveu sintomas severos de fitointoxicação (100\%), comprovando 
Tabela 4. Porcentagem de fitotoxicidade exibida pelo tomate cv. IPA 6 aos 7, 14, 21, 28 e 35 dias após a aplicação (DAA) de diuron e metribuzin cultivado em diferentes coberturas de solo. Tangará da Serra, MT. 2017.

\begin{tabular}{|c|c|c|c|c|c|}
\hline \multirow{2}{*}{ Avaliações } & \multirow{2}{*}{ Coberturas } & \multicolumn{3}{|c|}{ Herbicidas } & \multirow{2}{*}{ Médias } \\
\hline & & Diuron & Metribuzin & Testemunha & \\
\hline \multirow{5}{*}{7 DAA } & Solo exposto & $70,00 \mathrm{aA}$ & $70,00 \mathrm{aA}$ & $0,00 \mathrm{aB}$ & 46,67 \\
\hline & U. ruziziensis & $65,00 \mathrm{aA}$ & $20,00 \mathrm{bB}$ & $0,00 \mathrm{aC}$ & 28,33 \\
\hline & C. infestante & $85,00 \mathrm{aA}$ & $20,00 \mathrm{bB}$ & $0,00 \mathrm{aC}$ & 35,00 \\
\hline & P. glaucum & $85,00 \mathrm{aA}$ & $55,00 \mathrm{aA}$ & $0,00 \mathrm{aB}$ & 46,67 \\
\hline & Médias & 76,25 & 41,25 & 0,00 & $\mathrm{CV}=17,13 \%$ \\
\hline \multirow[t]{5}{*}{14 DAA } & Solo exposto & 100,00 & 40,00 & 0,00 & $46,67^{\mathrm{ns}}$ \\
\hline & U. ruziziensis & 100,00 & 20,00 & 0,00 & $40,00^{\text {ns }}$ \\
\hline & C. infestante & 100,00 & 20,00 & 0,00 & $40,00^{\mathrm{ns}}$ \\
\hline & P. glaucum & 100,00 & 40,00 & 0,00 & $46,67^{\mathrm{ns}}$ \\
\hline & Médias & $100,00 \mathrm{~A}$ & $30,00 \mathrm{~B}$ & $0,00 \mathrm{C}$ & $\mathrm{CV}=21,11 \%$ \\
\hline \multirow[t]{5}{*}{21 DAA } & Solo exposto & 100,00 & 40,00 & 0,00 & $46,67^{\mathrm{ns}}$ \\
\hline & U. ruziziensis & 100,00 & 20,00 & 0,00 & $40,00^{\mathrm{ns}}$ \\
\hline & C. infestante & 100,00 & 20,00 & 0,00 & $40,00^{\text {ns }}$ \\
\hline & P. glaucum & 100,00 & 40,00 & 0,00 & $46,67^{\text {ns }}$ \\
\hline & Médias & $100,00 \mathrm{~A}$ & $30,00 \mathrm{~B}$ & $0,00 \mathrm{C}$ & $\mathrm{CV}=21,11 \%$ \\
\hline \multirow[t]{5}{*}{28 DAA } & Solo exposto & 100,00 & 25,00 & 0,00 & $41,67^{\mathrm{ns}}$ \\
\hline & U. ruziziensis & 100,00 & 0,00 & 0,00 & $33,33^{\text {ns }}$ \\
\hline & C. infestante & 100,00 & 0,00 & 0,00 & $33,33^{\text {ns }}$ \\
\hline & P. glaucum & 100,00 & 25,00 & 0,00 & $41,67^{\mathrm{ns}}$ \\
\hline & Médias & $100,00 \mathrm{~A}$ & $12,50 \mathrm{~B}$ & $0,00 \mathrm{~B}$ & $\mathrm{CV}=37,81 \%$ \\
\hline \multirow[t]{5}{*}{35 DAA } & Solo exposto & 100,00 & 25,00 & 0,00 & $41,67^{\mathrm{ns}}$ \\
\hline & U. ruziziensis & 100,00 & 0,00 & 0,00 & $33,33^{\text {ns }}$ \\
\hline & C. infestante & 100,00 & 0,00 & 0,00 & $33,33^{\text {ns }}$ \\
\hline & P. glaucum & 100,00 & 25,00 & 0,00 & $41,67^{\text {ns }}$ \\
\hline & Médias & $100,00 \mathrm{~A}$ & $12,50 \mathrm{~B}$ & $0,00 \mathrm{~B}$ & $\mathrm{CV}=37,81 \%$ \\
\hline
\end{tabular}

Médias seguidas de mesma letra, maiúscula na linha e minúscula na coluna, não diferem entre si pelo teste de Scott-Knott $(p<0,05)$; ns não significativo; CV = Coeficiente de Variação.

que não é seletivo à cultura quando aplicado na modalidade pré-transplante e na dose de $96 \mathrm{~g} \mathrm{ha}^{-1}$.

A mesma severidade de danos foi verificada por Souza et al. (2014) que obtiveram fitointoxicação de $100 \%$, em plantas de crambe (Crambe abyssinica Hochst) submetidas à aplicação de diuron na dose de $1.200 \mathrm{~g} \mathrm{ha}^{-1}$ e na modalidade pré-emergência. Na presente pesquisa, observou-se que as mudas transplantas aos 7 DAA de diuron, apresentavam clorose e necrose das folhas, com consequente redução do porte e da área fotossinteticamente ativa. $\mathrm{O}$ avanço dos sintomas, decorrente da destruição do fotossistema II das plantas resultaram na morte total das mesmas aos 14 DAA.

Quanto ao controle de plantas daninhas por ambos os herbicidas, notou-se que todos os tratamentos com aplicação de diuron e metribuzin foram semelhantes aos 7, 14 e 21 DAA, proporcionando excelente eficácia ( $>91 \%$ ) de controle nestas avaliações (Tabela 5).

Esses resultados confirmaram a premissa de que o emprego de coberturas no manejo de plantas daninhas complementa o controle químico, visto que as maiores notas de eficácia foram 
Tabela 5. Porcentagem de controle de plantas daninhas aos 7, 14, 21, 28 e 35 dias após a aplicação (DAA) de diuron e metribuzin em tomate cultivado com diferentes plantas de cobertura. Tangará da Serra, MT. 2017.

\begin{tabular}{|c|c|c|c|c|c|}
\hline \multirow{2}{*}{ Avaliações } & \multirow{2}{*}{ Coberturas } & \multicolumn{3}{|c|}{ Herbicidas } & \multirow{2}{*}{ Médias } \\
\hline & & Diuron & Metribuzin & Testemunha & \\
\hline \multirow{5}{*}{7 DAA } & Solo exposto & $100,00 \mathrm{aA}$ & $100,00 \mathrm{aA}$ & $0,00 \mathrm{bB}$ & 66,67 \\
\hline & U. ruziziensis & $100,00 \mathrm{aA}$ & $100,00 \mathrm{aA}$ & $90,00 \mathrm{aA}$ & 96,67 \\
\hline & C. infestante & $100,00 \mathrm{aA}$ & $100,00 \mathrm{aA}$ & $100,00 \mathrm{aA}$ & 100 \\
\hline & P. glaucum & $100,00 \mathrm{aA}$ & $100,00 \mathrm{aA}$ & $95,00 \mathrm{aA}$ & 98,33 \\
\hline & Médias & 100,00 & 100,00 & 71,25 & $\mathrm{CV}=5,69 \%$ \\
\hline \multirow[t]{5}{*}{14 DAA } & Solo exposto & $100,00 \mathrm{aA}$ & $100,00 \mathrm{aA}$ & $0,00 \mathrm{bB}$ & 66,67 \\
\hline & U. ruziziensis & $100,00 \mathrm{aA}$ & $100,00 \mathrm{aA}$ & $85,00 \mathrm{aB}$ & 95,00 \\
\hline & C. infestante & $100,00 \mathrm{aA}$ & $100,00 \mathrm{aA}$ & $90,00 \mathrm{aA}$ & 96,67 \\
\hline & P. glaucum & $100,00 \mathrm{aA}$ & $100,00 \mathrm{aA}$ & $90,00 \mathrm{aA}$ & 96,67 \\
\hline & Médias & 100,00 & 100,00 & 66,25 & $\mathrm{CV}=10,13 \%$ \\
\hline \multirow[t]{5}{*}{21 DAA } & Solo exposto & $95,00 \mathrm{aA}$ & $100,00 \mathrm{aA}$ & $0,00 \mathrm{cB}$ & 65,00 \\
\hline & U. ruziziensis & $100,00 \mathrm{aA}$ & $95,00 \mathrm{aA}$ & $70,00 \mathrm{bB}$ & 88,33 \\
\hline & C. infestante & $100,00 \mathrm{aA}$ & $100,00 \mathrm{aA}$ & $80,00 \mathrm{aB}$ & 93,33 \\
\hline & P. glaucum & $100,00 \mathrm{aA}$ & $100,00 \mathrm{aA}$ & $80,00 \mathrm{aB}$ & 93,33 \\
\hline & Médias & 98,75 & 98,75 & 66,25 & $\mathrm{CV}=16,16 \%$ \\
\hline \multirow[t]{5}{*}{28 DAA } & Solo exposto & 95,00 & 100,00 & 0,00 & $65,00^{\mathrm{ns}}$ \\
\hline & U. ruziziensis & 100,00 & 90,00 & 62,50 & $84,17^{\text {ns }}$ \\
\hline & C. infestante & 100,00 & 100,00 & 70,00 & $90,00^{\text {ns }}$ \\
\hline & P. glaucum & 100,00 & 95,00 & 72,50 & $89,17^{\text {ns }}$ \\
\hline & Médias & $98,75 \mathrm{~A}$ & $96,25 \mathrm{~A}$ & $51,25 \mathrm{~B}$ & $\mathrm{CV}=22,61 \%$ \\
\hline \multirow[t]{5}{*}{35 DAA } & Solo exposto & 90,00 & 100,00 & 0,00 & $63,33^{\text {ns }}$ \\
\hline & U. ruziziensis & 100,00 & 85,00 & 48,75 & $77,92^{\mathrm{ns}}$ \\
\hline & C. infestante & 100,00 & 100,00 & 53,75 & $84,58^{\text {ns }}$ \\
\hline & P. glaucum & 100,00 & 90,00 & 52,50 & $80,83^{\text {ns }}$ \\
\hline & Médias & $97,50 \mathrm{~A}$ & $93,75 \mathrm{~A}$ & $38,75 \mathrm{~B}$ & $\mathrm{CV}=25,71 \%$ \\
\hline
\end{tabular}

Médias seguidas de mesma letra, maiúscula na linha e minúscula na coluna, não diferem entre si pelo teste de Scott-Knott a $p<0,05$ de probabilidade; ${ }^{\text {ns }}$ não significativo; $C V=$ Coeficiente de Variação.

visualizadas quando foi implantada a integração dos métodos de controle. Dessa forma, tais tratamentos apresentaram um menor percentual de germinação de plantas daninhas durante o período da pesquisa. Tal complementação potencializa a eficácia do manejo de plantas daninhas em um sistema de cultivo, demonstrando que a cobertura morta pode ser uma ferramenta introduzida com sucesso no tomate, corroborando com as ressalvas de Castro et al. (2016) e Dimande (2016), que afirmaram que essa pode ser usada com êxito em culturas da família Solanaceae.
Neste contexto, Guimarães et al. (2002) salientaram que as coberturas servem como um instrumento dentro do manejo integrado que limita a passagem de luz, bloqueando a germinação de sementes de plantas daninhas fotoblásticas positivas, e em muitos casos reduzindo a utilização de herbicidas. A baixa germinação de plantas daninhas no presente estudo deveu-se, provavelmente, ao efeito físico e alelopático que as coberturas usadas propiciaram. Esse último efeito pode ocorrer principalmente, sabendo da capacidade alelopática das palhadas de U. ruziziensis e P. glaucum (Correia et al., 
2006; Tokura e Nóbrega, 2006; Monquero et al., 2009; Nepomuceno et al., 2012).

É válido ressaltar, além dos tratamentos supracitados, os efeitos da cobertura proporcionada pela comunidade infestante, caracterizada pela diversidade de espécies de plantas daninhas que a compunham, sendo que capim-camalote (Rottboellia cochinchinensis), poaia-branca (Richardia brasiliensis), apaga-fogo (Alternanthera tenella), erva-de-passarinho (Stellaria media) e corda-de-viola (Ipomoea purpurea) foram as de maior importância (Tabela 1), permitindo levantar a hipótese de que a palhada destas plantas gerou um impedimento físico, e talvez alelopático sobre a germinação de outras infestantes. Desta forma, Cândido et al. (2010) observaram que a parte aérea de fedegoso (Senna occidentalis L.) apresentou potencial alelopático sobre a germinação e crescimento inicial de plantas daninhas tanto eudicotiledôneas como monocotiledôneas. Essa espécie foi encontrada no levantamento da comunidade infestante e, possivelmente foi um dos fatores que contribuiu para o sucesso desse tratamento.

Oliveira et al. (2011) obtiveram em seus estudos que o extrato aquoso das folhas de falsa-serralha (Emilia sonchifolia) inibiu de modo significativo a germinação de sementes de sorgo, pepino e picão preto, evidenciando o potencial alelopático dessa espécie. Na presente pesquisa, encontrou-se outra espécie do mesmo gênero, que possivelmente pode ter também tal efeito sobre a germinação de daninhas no cultivo de tomate.

A avaliação realizada aos $14 \mathrm{DAA}$, indicou que não houve diferença entre as coberturas para os herbicidas aplicados, sendo que a comunidade infestante e $P$. glaucum foram semelhantes para testemunha, diuron e metribuzin (Tabela 5). A menor eficácia foi aferida na testemunha sem aplicação e em solo exposto, considerada, nesse caso, o tratamento controle.

Apesar da decomposição das palhadas, a combinação do diuron com as coberturas foi eficiente em todos os períodos de avaliação, reforçando o argumento de que as coberturas complementam o controle químico, não havendo diferença entre as coberturas vegetais analisadas. Ronchi et al. (2010) salientaram que é fundamental que o controle químico seja feito em conjunto com outras técnicas, sobretudo empregando coberturas ou palhadas, a fim de melhorarem as condições de desenvolvimento da cultura, cabendo ao controle químico apenas complementar quando necessário.

Os tratamentos que apresentaram melhor controle $(>91 \%)$ sobre as plantas daninhas foram as coberturas de comunidade infestante e P. glaucum, seja em associação com ambos os herbicidas, ou sem aplicação dos mesmos (Tabela 5). Isso pode estar relacionado à taxa mais lenta de decomposição dessas, em comparação à U. ruziziensis. Além disso, as diferentes quantidades de palhada aplicadas influenciaram na ação dos tratamentos, ressaltando-se que P. glaucum e comunidade tinham os maiores valores. No entanto, esses dados divergem dos de Hirata et al. (2009) que ao estudarem diferentes coberturas, notaram que a comunidade infestante usada como palhada promoveu uma redução na cobertura do solo e juntamente com o tratamento sem cobertura, possibilitou elevada emergência de plantas daninhas.

Constatou-se que o solo exposto sem aplicação foi menos eficiente, permitindo uma maior infestação de plantas daninhas, sobretudo eudicotiledôneas. Com isso, foram identificadas aos 35 DAA, as plantas daninhas emergidas nos tratamentos, destacando a diversidade de daninhas eudicotiledôneas (Tabela 3). Ao estudarem diferentes palhadas na cultura do tomate, Silva e Mueller (2010) também verificaram a ocorrência predominante de plantas daninhas dessa classe.

A altura de plantas não foi influenciada pelas coberturas, mas pelos herbicidas empregados (Tabela 6). Dessa maneira, notou-se que, apesar dos danos promovidos nos primeiros dias após o transplante, o tomate submetido à aplicação de metribuzin (480 $\left.\mathrm{g} \mathrm{ha}^{-1}\right)$, conseguiu crescer adequadamente. O diuron, por sua vez, promoveu 
Tabela 6. Altura (cm) de plantas do tomate cv. IPA 6 aos 7, 14, 21, 28 e 35 dias após a aplicação (DAA) de diuron e metribuzin. Tangará da Serra, MT. 2017.

\begin{tabular}{|c|c|c|c|c|c|}
\hline \multirow{2}{*}{ Avaliações } & \multirow{2}{*}{ Coberturas } & \multicolumn{3}{|c|}{ Herbicidas } & \multirow{2}{*}{ Médias } \\
\hline & & Diuron & Metribuzin & Testemunha & \\
\hline \multirow{5}{*}{7 DAA } & Solo exposto & 7,20 & 11,00 & 16,30 & $11,50^{\mathrm{ns}}$ \\
\hline & U. ruziziensis & 8,00 & 15,50 & 16,30 & $13,27^{\text {ns }}$ \\
\hline & C. infestante & 2,60 & 15,90 & 18,00 & $12,17^{\mathrm{ns}}$ \\
\hline & P. glaucum & 4,20 & 10,90 & 16,90 & $10,67^{\mathrm{ns}}$ \\
\hline & Médias & $5,5 \mathrm{C}$ & $13,32 \mathrm{~B}$ & $16,88 \mathrm{~A}$ & $\mathrm{CV}=30,29 \%$ \\
\hline \multirow[t]{5}{*}{14 DAA } & Solo exposto & 0,00 & 15,40 & 20,10 & $11,83^{\text {ns }}$ \\
\hline & U. ruziziensis & 1,60 & 21,00 & 20,70 & $15,30^{\mathrm{ns}}$ \\
\hline & C. infestante & 0,00 & 21,70 & 23,30 & $15,00^{\text {ns }}$ \\
\hline & P. glaucum & 0,00 & 15,70 & 21,10 & $12,27^{\mathrm{ns}}$ \\
\hline & Médias & $0,40 \mathrm{~B}$ & $18,45 \mathrm{~A}$ & $21,30 \mathrm{~A}$ & $\mathrm{CV}=33,01 \%$ \\
\hline \multirow[t]{5}{*}{21 DAA } & Solo exposto & 0,00 & 21,00 & 25,50 & $15,50^{\mathrm{ns}}$ \\
\hline & U. ruziziensis & 0,00 & 28,30 & 24,30 & $17,53^{\text {ns }}$ \\
\hline & C. infestante & 0,00 & 29,80 & 28,40 & $19,40^{\text {ns }}$ \\
\hline & P. glaucum & 0,00 & 20,30 & 27,10 & $15,80^{\mathrm{ns}}$ \\
\hline & Médias & $0,00 \mathrm{~B}$ & $24,85 \mathrm{~A}$ & $26,32 \mathrm{~A}$ & $\mathrm{CV}=34,68 \%$ \\
\hline \multirow[t]{5}{*}{28 DAA } & Solo exposto & 0,00 & 24,40 & 29,40 & $17,93^{\text {ns }}$ \\
\hline & U. ruziziensis & 0,00 & 36,00 & 32,40 & $22,80^{\text {ns }}$ \\
\hline & C. infestante & 0,00 & 38,20 & 35,90 & $24,70^{\mathrm{ns}}$ \\
\hline & P. glaucum & 0,00 & 29,10 & 35,20 & $21,43^{\text {ns }}$ \\
\hline & Médias & $0,00 \mathrm{~B}$ & $31,92 \mathrm{~A}$ & $33,22 \mathrm{~A}$ & $\mathrm{CV}=34,78 \%$ \\
\hline \multirow[t]{5}{*}{35 DAA } & Solo exposto & 0,00 & 28,00 & 32,00 & $20,00^{\mathrm{ns}}$ \\
\hline & U. ruziziensis & 0,00 & 39,20 & 34,20 & $24,47^{\text {ns }}$ \\
\hline & C. infestante & 0,00 & 40,90 & 38,70 & $26,53^{\text {ns }}$ \\
\hline & P. glaucum & 0,00 & 30,80 & 37,80 & $22,87^{\text {ns }}$ \\
\hline & Médias & $0,00 \mathrm{~B}$ & $34,72 \mathrm{~A}$ & $35,68 \mathrm{~A}$ & $\mathrm{CV}=34,80 \%$ \\
\hline
\end{tabular}

Médias seguidas de mesma letra, maiúscula na linha e minúscula na coluna, não diferem entre si pelo teste de

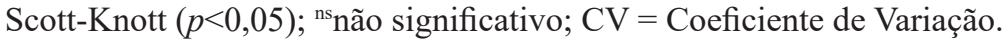

elevados sintomas de fitointoxicação que reduziram drasticamente a altura de plantas.

Aos 35 DAA, foram mensuradas as massas secas de folhas, caule e raízes, verificando-se que houve interação entre herbicida e cobertura para todas as partes vegetais avaliadas (Tabela 7). Na massa seca de folhas, observou-se, para a testemunha, que as coberturas de $P$. glaucum e comunidade infestante destacaram-se com os maiores valores de massa (Tabela 7), validando a justificativa de que a maior proteção do solo com palhadas favorece o crescimento das plantas, já que minimizam a germinação e, posterior interferência negativa das plantas daninhas (Oliveira et al., 2002).
Em contrapartida, os tratamentos U. ruziziensis e comunidade infestante com pulverização de metribuzin, sobressaíram-se à testemunha, evidenciando os maiores valores de massa seca de folhas (Tabela 7). Ao aferir a massa seca de caule, notou-se que somente os tratamentos testemunha e comunidade infestante foram inferiores à mesma cobertura, porém com aplicação de metribuzin (Tabela 7), sendo que os demais tratamentos, neste caso: solo exposto; U. ruziziensis e P. glaucum sem e com aplicação de metribuzin foram similares.

Esses resultados decorrem do fato de que o emprego da cobertura morta nos vasos em 
Tabela 7. Massa seca de folhas, caule e raiz do tomate cv. IPA 6, aferida aos 35 dias após a aplicação (DAA) de diuron e metribuzin. Tangará da Serra, MT. 2017.

\begin{tabular}{|c|c|c|c|c|c|}
\hline \multirow{2}{*}{ Avaliações } & \multirow{2}{*}{ Coberturas } & \multicolumn{3}{|c|}{ Herbicidas } & \multirow[b]{2}{*}{ Médias } \\
\hline & & Diuron & Metribuzin & Testemunha & \\
\hline \multirow[t]{5}{*}{ Massa seca de folhas } & Solo exposto & $0,00 \mathrm{aB}$ & $0,36 \mathrm{cA}$ & $0,37 \mathrm{bA}$ & 0,24 \\
\hline & U. ruziziensis & $0,00 \mathrm{aC}$ & $1,01 \mathrm{bA}$ & $0,48 \mathrm{bB}$ & 0,50 \\
\hline & C. infestante & $0,00 \mathrm{aC}$ & $1,39 \mathrm{aA}$ & $0,67 \mathrm{aB}$ & 0,69 \\
\hline & P. glaucum & $0,00 \mathrm{aB}$ & $0,50 \mathrm{cA}$ & $0,57 \mathrm{aA}$ & 0,36 \\
\hline & Médias & 0,00 & 0,82 & 0,52 & $\mathrm{CV}=5,26 \%$ \\
\hline \multirow[t]{5}{*}{ Massa seca de caule } & Solo exposto & $0,00 \mathrm{aB}$ & $0,23 \mathrm{bA}$ & $0,24 \mathrm{bA}$ & 0,16 \\
\hline & U. ruziziensis & $0,00 \mathrm{aB}$ & $0,35 \mathrm{bA}$ & $0,29 \mathrm{bA}$ & 0,21 \\
\hline & C. infestante & $0,00 \mathrm{aC}$ & $0,71 \mathrm{aA}$ & $0,48 \mathrm{aB}$ & 0,40 \\
\hline & P. glaucum & $0,00 \mathrm{aB}$ & $0,27 \mathrm{bA}$ & $0,24 \mathrm{bA}$ & 0,17 \\
\hline & Médias & 0,00 & 0,39 & 0,31 & $\mathrm{CV}=6,34 \%$ \\
\hline \multirow[t]{5}{*}{ Massa seca de raiz } & Solo exposto & $0,00 \mathrm{aB}$ & $0,41 \mathrm{cA}$ & $0,49 \mathrm{cA}$ & 0,30 \\
\hline & U. ruziziensis & $0,00 \mathrm{aC}$ & $0,68 \mathrm{bB}$ & $1,79 \mathrm{aA}$ & 0,82 \\
\hline & C. infestante & $0,00 \mathrm{aB}$ & $1,20 \mathrm{aA}$ & $0,97 \mathrm{bA}$ & 0,72 \\
\hline & P. glaucum & $0,00 \mathrm{aB}$ & $0,36 \mathrm{cA}$ & $0,46 \mathrm{cA}$ & 0,27 \\
\hline & Médias & 0,00 & 0,66 & 0,93 & $\mathrm{CV}=8,08 \%$ \\
\hline
\end{tabular}

Médias seguidas de mesma letra, maiúscula na linha e minúscula na coluna, não diferem entre si pelo teste de Scott-Knott $(p<0,05) ; \mathrm{CV}=$ Coeficiente de Variação.

integração com o metribuzin reduziu a incidência de plantas daninhas, estimulando o desenvolvimento do tomate e aumentando a massa seca tanto de folhas quanto de caule. Em consonância, Resende et al. (2005) ao estudarem o cultivo de verão da cenoura, notaram que a utilização de cobertura morta favoreceu o desenvolvimento da cultura, visto que melhorou as características hidrotérmicas do solo.

Quanto à massa seca de raízes, todos os tratamentos sem aplicação foram estatisticamente semelhantes ao metribuzin, com exceção do tratamento $U$. ruziziensis e metribuzin, que evidenciou a menor média de massa seca de raízes (Tabela 7). O maior valor de massa seca de raízes foi constatado no tratamento testemunha e $U$. ruziziensis, provavelmente em razão da menor quantidade de cobertura, que contribuiu para acelerar a decomposição do material, com consequente fornecimento de nutrientes e bom desenvolvimento de raiz (Queiroga et al., 2002; Belan et al., 2013).
Ao final do estudo, registrou-se que nos tratamentos em que houve morte de plantas, como ocorreu com as plantas transplantadas após a aplicação do diuron, a massa foi zero e, dentre os demais tratamentos, apenas o metribuzin com U. ruziziensis não apresentou valores semelhantes à testemunha, demonstrando assim, que mesmo com os danos iniciais causados pela aplicação do metribuzin, as palntas de tomate desenvolveram-se normalmente durante o período de avaliação.

\section{Conclusões}

A cobertura do solo com Brachiaria ruziziensis, Pennisetum glaucum e comunidade infestante complementa a ação dos herbicidas metribuzin e diuron. Além disso, os resultados demonstram que o metribuzin promove injúrias leves de fitointoxicação nas mudas, mas sem refletir em perdas na biomassa seca. Apesar da eficácia no controle das plantas daninhas, o diuron não é seletivo ao tomate, causando altos percentuais de fitointoxicação. 


\section{Referências}

Asociación Latino Americana de Malezas ALAM. Recomendaciones sobre unificación de los sistemas de evolucion en ensayos de control de malezas. Bogotá: ALAM, 1974.

Bachega, T.F.; Hernandez, D.D.; Alves, L.C.A. Tomate: tolerância sob medida. Cultivar Hortaliças e Frutas, n.31, p.10-14, 2005.

Belan, L.L.; Xavier, T.M.T.; Torres, H.; Toledo, J.V.; Pezzopane, J.E.M. Dinâmica entre temperaturas do ar e do solo sob duas condições de cobertura. Revista Acadêmica, v. 11, n.1, p.147-154, 2013.

Brasil. Ministério da Agricultura, Pecuária e Abastecimento. AGROFIT - Sistema de Agrotóxicos Fitossanitários. Brasília, 2018. Disponível em: <http://agrofit.agricultura.gov. br/agrofit_cons/principal_agrofit_cons $>$. Acesso em: 19 mar. 2018.

Cândido, A.C.S.; Schmidt, V.; Laura, V.A.; Faccenda, O.; Hess, S.C.; Simionatto, E.; Peres, M.T.L.P. Potencial alelopático da parte aérea de Senna occidentalis (L.) Link (Fabaceae, Caesalpinioideae): bioensaios em laboratório. Acta Botanica Brasílica, v.24, n.1, p.235-242, 2010.

Castro, Y.O.; Cavalieri, S.D.; Santos, M.P.; Golynski, A.; Nascimento, A.R. Manejo integrado de plantas daninhas na cultura do tomate para processamento industrial e para consumo in natura. Scientific Eletronic Archives, v.9, n.5, p.11-17, 2016.

Correia, N.M.; Durigan, J.C.; Klink, U.P. Influência do tipo e da quantidade de resíduos vegetais na emergência de plantas daninhas. Planta Daninha, v.24, n.2, p.245-253, 2006.

Dimande, P. Desempenho dos métodos de controle de infestantes no tomate sob variação dos dias de rega. International Journal of Scientific \& Engineering Research, v.7, n.9, p.619-624, 2016.
Empresa Brasileira de Pesquisa Agropecuária EMBRAPA. Sistema Brasileiro de Classificação de Solos. Brasília: EMBRAPA Solos, 2013. 353p.

Filgueira, F.A.E. Novo manual de olericultura: agrotecnologia moderna na produção e comercialização de hortaliças. Viçosa: Editora UFV, 2008. cap.13, p.216-224.

Guimarães, S.C.; Souza, I.F.; Pinho, E.V.R.V. Emergência de Tridax procumbens em função da profundidade de semeadura, do conteúdo de argila no substrato e da incidência de luz na semente. Planta Daninha, v.20, n.3, p.413-419, 2002.

Hirata, A.C.S.; Hirata, E.K.; Monquero, P.A.; Golla, A.R.; Narita, N. Plantas de cobertura no controle de plantas daninhas na cultura do tomate em plantio direto. Planta Daninha, v.27, n.3, p.465-472, 2009.

Monquero, P.A.; Amaral, L.R.; Inácio, E.M.; Brunhara, J.P.; Binha, D.P.; Silva, P.V.; Silva, A.C. Efeito de adubos verdes na supressão de espécies de plantas daninhas. Planta Daninha, v.27, n.1, p.85-95, 2009.

Nascente, A.S.; Pereira, W.; Medeiros, M.A. Interferência das plantas daninhas na cultura do tomate para processamento. Horticultura Brasileira, v.22, n.3, p.602-606, 2004.

Nepomuceno, M.P.; Varela, R.M.; Alves, P.L.C.A.; Martins, J.V.F. Períodos de dessecação de Urochloa ruziziensis e seu reflexo na produtividade da soja RR. Planta Daninha, v.30, n.3, p.557-565, 2012.

Oliveira Júnior, R.S. Mecanismo de ação de herbicidas. In: Oliveira Júnior, R.S.; Constantin, J.; Inoue, M.H. (Ed.). Biologia e manejo de plantas daninhas. Curitiba: Omnipax, 2011. cap.7, p.141-191.

Oliveira, L.G.A.; Belinelo, V.J.; Almeida, M.S.; Aguilar, E.B.; Vieira Filho, S.A. Alelopatia de Emilia sonchifolia (L.) Dc. (Asteraceae) na germinação e crescimento inicial de sorgo, pepino e picão preto. Enciclopédia Biosfera, v.7, n.12, p.1-10, 2011. 
Oliveira, T.K.; Carvalho, G.J.; Moraes, R.N.S. Plantas de cobertura e seus efeitos sobre o feijoeiro em plantio direto. Pesquisa Agropecuária Brasileira, v.37, n.8, p.1079-1087, 2002.

Ormeño, N.J.; Fuentes, V.F.; Soffia, C.V. Tolerancia del tomate (Lycopersicon esculentum Mill.) a aplicaciones post transplante del herbicida halosulfuron-metil. Agricultura Técnica, v.63, n.2, p.125-134, 2003.

Perim, L.; Toledo, R.E.B.; Negrisoli, E.; Corrêa, M.R.; Carbonari, C.A.; Rossi, C.V.S.; Velini, E.D. Eficácia do herbicida amicarbazone no controle em pós-emergência de espécies de corda-de-viola (Ipomoea grandifolia e Merremia cissoids). Revista Brasileira de Herbicidas, v.8, n.1, p.19-26, 2009.

Queiroga, R.C.F.; Nogueira, I.C.C.; Bezerra Neto, F.; Moura, A.R.B.; Pedrosa, J.F. Utilização de diferentes materiais como cobertura morta do solo no cultivo de pimentão. Horticultura Brasileira, v.20, n.3, p.416-418, 2002.

Resende, F.V.; Souza, L.S.; Oliveira, P.S.R.; Gualberto, R. Uso de cobertura morta vegetal no controle da umidade e temperatura do solo, na incidência de plantas invasoras e na produção da cenoura em cultivo de verão. Ciência e Agrotecnologia, v.29, n.1, p.100-105, 2005.

Ronchi, C.P.; Serrano, L.A.L.; Silva, A.A.; Guimarães, O.R. Manejo de plantas daninhas na cultura do tomateiro. Planta Daninha, v.28, n.1, p.215-228, 2010.

Silva, B.P.; Carvalho, L.B.; Alves, P.L.C.A.; Souza, M.C.; Magário, F.B. Interferência de caruru-de-mancha, maria-pretinha, picão-preto e tiririca em tomateiro industrial. Bragantia, v.69, n.2, p.313-318, 2010.

Silva, L.; Mueller, S. Avaliação de coberturas vegetais no solo sobre a incidência de plantas daninhas e na produtividade de tomate. Ágora, v.17, n.1, p.12-19, 2010.

Sociedade Brasileira da Ciência das Plantas Daninhas - SBCPD. Procedimentos para instalação, avaliação e análise de experimentos com herbicidas. Londrina: SBCPD, 1995. 42p.

Souza, G.S.F.; Vitorino, H.S.; Fioreze, A.C.C.L.; Pereira, M.R.R.; Martins, D. Seletividade de herbicidas na cultura de crambe. Semina: Ciências Agrárias, v.35, n.1, p.161-168, 2014.

Tokura, L.K.; Nóbrega, L.H.P. Alelopatia de cultivos de cobertura vegetal sobre plantas infestantes. Acta Scientiarum. Agronomy, v.28, n.3, p.379-384, 2006.

Valmorbida, J.; Wamser, A.F.; Suzuki, A.; Santin, B.L.; Ender, M.M. Sistemas de manejo e culturas de cobertura do solo para o tomateiro tutorado. Horticultura Brasileira, v.30, n.2, p.3183-3189, 2012.

Vargas, L.; Adegas, F.; Gazziero, D.; Karam, D.; Agostinetto, D.; Silva, W.T. Resistência de plantas daninhas a herbicidas no Brasil: histórico, distribuição, impacto econômico, manejo e prevenção. In: Meschede, D.K.; Gazziero, D.L.P. (Ed.). A era Glyphosate: agricultura, meio ambiente e homem. Londrina: Midiograf II, 2016. cap.20, p.219-239.

Wamser, A.F.; Valmorbida, J.; Mueller, S.; Gonçalves, M.M.; Feltrim, A.L. Produtividade de tomate em função de sistemas de plantio e plantas de cobertura do solo. Horticultura Brasileira, v.28, n.2, p.1652-1656, 2010. 